\title{
Colonialidade, Modernidade e Decolonialidade: Da Naturalização da Guerra à Violência Sistêmica*
}

\author{
Coloniality, Modernity and Decoloniality: From the Naturalization of War to Systemic \\ Violence
}

\section{Emerson Oliveira do Nascimento}

Doutor em ciência política pela Universidade Federal de Pernambuco Professor do Instituto de Ciências Sociais e do Programa de Pós-Graduação em Sociologia da

Universidade Federal de Alagoas emersondonascimento@yahoo.com.br

Resumo: A teoria decolonial compreende que colonização e modernidade, enquanto projetos ocidentais, são faces de uma mesma moeda e que o colonialismo, está longe de ser compreendido como uma etapa superada do passado das antigas colônias europeias. Nosso objetivo aqui é explorar a contribuição da teoria decolonial enquanto ferramenta analítica capaz de explicar a lógica inerente à condição de "guerra justa" contra os sujeitos colonizados no passado e sua dilatação e normalização hoje para a condição de uma espécie de "violência sistêmica" cujos alvos privilegiados ainda são os grupos étnicoraciais, de gênero e as sexualidades divergentes ou não-hegemônicas. Acreditamos que a insubmissão analítica que estas ferramentas ensejam podem vir a se configurar como conceitos potencializadores para a investigação social sobre violência, especialmente, na América Latina.

Palavras-chave: colonialidade; modernidade; decolonialidade; guerra justa; violência.

\begin{abstract}
The decolonial theory understands that colonization and modernity as Western projects, are sides of the same coin and that colonialism is far from being understood as outdated stage of the past of the former European colonies. Our objective here is to explore the contribution of decolonial theory as an analytical tool capable of explaining the logic inherent in the condition of "just war" against colonized subjects in the past and its expansion and normalization today into the condition of a kind of "systemic violence" whose privileged targets are still ethnic-racial groups, gender and divergent or nonhegemonic sexualities. We believe that the analytical non-submission that these tools give rise to may come to be configured as potential concepts for social investigation on violence, especially in Latin America.
\end{abstract}

Keywords: coloniality; modernity; decoloniality; just war; violence.

\footnotetext{
* Agradeço os comentários e sugestões apresentados pelos avaliadores sobre a versão preliminar desse artigo e atesto que suas recomendações foram fundamentais para o aprimoramento do argumento central.
} 


\section{À guisa de apresentação}

Os estudos decoloniais admitem como referência, o pressuposto de que o colonialismo enquanto um processo social e histórico não se reproduziu através do tempo somente por meios econômicos e políticos, mas também através da institucionalização e da padronização de modelos cognitivos de existência e de conhecimento que sobreviveram mesmo após a emancipação das colônias europeias (BERNARDINO-COSTA, MADONADO-TORRES \& GROSFOGUEL, 2018). Nesse sentido, para os teóricos deste programa de pesquisa, há que se destacar, desde o princípio, as distinções elementares entre colonialismo e colonialidade. De acordo com Aníbal Quijano (1991), o colonialismo compreende uma relação de dominação direta, política, social e cultural dos europeus sobre os povos conquistados de todos os continentes, caracterizando-se, portanto, como um fenômeno datado. A colonialidade, de outro modo, mas por continuidade, se refere ao entendimento de que o fim dos empreendimentos coloniais não compreendeu o fim da dominação colonial. A colonialidade, nesse sentido, nos dirá o autor, é uma espécie de continuação desta dominação, mesmo após superado o pacto colonial.

A noção de decolonialidade, portanto, apresenta-se como uma via teórica e prática de desconstruir padrões, conceitos e perspectivas impostas aos povos colonizados há séculos, além de perfazer ainda uma crítica radical à modernidade e ao capitalismo. Como defende Walter Mignolo (2007), o pensamento decolonial emergiu como um movimento de contraposição inerente à fundação da própria modernidade, tomando corpo, especialmente, na América Latina e nos contextos asiáticos e africanos; no primeiro caso, em função da resistência do pensamento indígena e afro-caribenho e, no segundo, em associação ao movimento de contraposição ao imperialismo britânico e ao colonialismo francês.

Conquanto, à despeito da crítica pós-colonial construída na Ásia e na África, o movimento decolonial surgirá como uma posição epistemológica divergente e insurgente, especialmente, entre os/as intelectuais latino-americanos/as, sobretudo a partir da criação do grupo Modernidad/Colonialidad (M/C), fundado ainda no final da década de 1990 (BALLESTRIN, 2020). O grupo propunha uma radicalização do argumento pós-colonial, criticando o núcleo teórico do argumento, vinculado ao pósestruturalismo francês. Os autores do decolonialismo reclamavam uma ruptura crítica com a genealogia do pensamento europeu e reivindicavam para si uma base teórica mais 
genuína e autóctone, um verdadeiro "giro teórico", capaz de destacar as especificidades dos povos colonizados e servir ainda como um modelo de resistência à lógica da modernidade/colonialidade (MIGNOLO, 2008; BALLESTRIN, 2013).

O chamado "giro decolonial" pode ser entendido, nesse sentido, enquanto uma atitude epistemológica radical de insubordinação aos modelos ontológicos e epistemológicos de inspiração eurocêntrica por entender que estes modelos também circunscrevem um projeto de sujeição e dominação dos povos colonizados (CASTROGOMEZ \& GROSFOGUEL, 2007; MIGNOLO, 2010; LANDER, 2000). Não por acaso, as questões que a decolonialidade traz à tona desconcertam e descentralizam a aparente segurança do sujeito-cidadão moderno e os pilares das instituições políticas modernas, posto que concilia a ação intelectual à atitude política dentro e fora da academia. Por isso mesmo, é difícil delimitar a decolonialidade como um mero conjunto de teorias (embora seja nosso objetivo aqui depurar seus pressupostos analíticos), visto que ela pode e deve ser melhor compreendida como uma atitude de resistência intelectual, política, literária, artística e poética contra a lógica da colonialidade.

A teoria decolonial inverte os pólos da lógica da colonialidade não somente por que discute e denuncia o significado e a sobrevivência da colonização sob outros modos, mas também por que assume o desafio de atribuir ao colonizado a condição de agente e de questionador, da experiência histórica da colonização, do significado e da importância da colonização e das próprias ferramentas cognoscentes de leitura e interpretação do mundo (ESCOBAR, 2003; DUSSEL, 2016). O “olhar” decolonial questiona o projeto moderno, eurocêntrico e ocidentalizado de ciência, jogando uma lente de denúncia sobre as bases discriminatórias sobre as quais se apoia a noção moderna de ciência. A decolonialidade, por conseguinte, não somente posiciona o colonizado na condição de sujeito cognoscente (em flagrante ruptura à tradição europeia que sempre lhe outorgou a condição de objeto), quanto questiona os pressupostos ontológicos e epistemológicos que historicamente orientaram e determinaram a nossa produção e aquisição de conhecimento (KILOMBA, 2016).

Em um mesmo movimento, síncrono e diacrônico, a teoria decolonial coloca em xeque os parâmetros de validade do conhecimento produzido pelo velho mundo e posiciona o sul global na condição de norte epistemológico. Um novo princípio orientador para explicação e interpretação do "processo civilizatório", cujo modelo canônico de desenvolvimento e modernização deixa de ser a Europa, em favor da compreensão de experiências plurais que levem em conta expressões culturais de grupos 
distintos e cosmovisões diferenciadas, especialmente, ameríndias e afro-diaspóricas (ARROYO, 2011; McEWAN, 2019). Trata-se, portanto, de transformar a pesquisa histórica e social num ato de resistência, explicitando as ideias e as ações de grupos que foram silenciados, perseguidos e deslegitimados pelo projeto de ciência e de sociedade que se materializou a partir do advento da chamada modernidade a partir do século XVI.

Neste artigo, vamos perfazer parte desse percurso analítico, dedicando especial atenção ao modo pelo qual o projeto decolonial retoma o paradigma da "guerra justa" para compreender a constituição de um projeto de desumanização dos sujeitos colonizados que toma início na modernidade, mas avança sobre a contemporaneidade. Para melhor desenvolver esse argumento, dividimos o presente texto em mais três seções. Na próxima, discorreremos sobre o processo de desnaturalização a partir do qual os teóricos da decolonialidade compreendem o binômio colonialidade/modernidade, explorando os argumentos que sustentam a rejeição, por parte destes, da tese da superioridade da modernidade ocidental, bem como, as distinções que a literatura especializada faz entre as noções de colonialismo, colonialidade, decolonialidade e descolonização. Em seguida, em outra seção, discutiremos de que forma este/as autores/as entendem que a colonialidade/modernidade empreendeu um processo de naturalização das condições da "guerra justa" junto aos povos colonizados. A ideia é explorar de que forma este processo está fincado hoje às práticas sistemáticas de violência contra negros, mulheres e homossexuais na região, demonstrando como a lógica de aniquilamento do "outro", própria da estrutura colonial, sobrevive à despeito da emancipação política das antigas colônias. Na última seção, apontaremos nossas conclusões, com destaque para o potencial heurístico que a teoria decolonial traz para o estudo dos processos de subjetivação de grupos em condição de vulnerabilidade, desferindo uma ruptura radical contra qualquer forma de humanidade subalternizada.

\section{Alguns conceitos elementares para a analítica decolonial}

O primeiro apontamento analítico importante do chamado pensamento decolonial compreende o exercício de descortinar a relação obscura entre o projeto colonial e a própria modernidade (MALDONADO-TORRES, 2018; QUIJANO, 1991). 
Para além do entendimento quase consensual que toma o colonialismo como um produto da modernidade, a teoria decolonial explora os limites dessa relação, mostrando que colonialismo e modernidade nascem juntos - o colonialismo não seria um marco da modernidade, mas a essência da própria modernidade. É através desse questionamento da noção de modernidade que o movimento decolonial expõe a dinâmica das relações de poder que dão suporte ao colonialismo enquanto um projeto político e é por meio disso também, que os teóricos da decolonialidade elaboram suas estratégias de transformação da realidade e sua insubordinação aos modelos eurocêntricos de colonização dos modos de ser e de se reconhecer.

A decolonialidade propõe um engajamento crítico contra as teorias da modernidade por entender que a colonialidade é parte constitutiva desse projeto de sociedade. A proposta decolonial, nesse sentido, vai desde uma crítica da colonialidade até a proposta de construção de um movimento insurgente capaz de romper com a base epistêmica moderna. É importante destacar aqui que a decolonialidade não deve ser confundida com pós-modernidade, visto que os autores decoloniais pretendem ir mais além e apostar, epistemologicamente, na construção de um conhecimento sobre bases epistêmicas ditas "não-modernas". Essa distinção é importante porque, em geral, os/as teóricos/as da pós-modernidade também se apoiam sobre uma crítica da modernidade, mas não, necessariamente, rompem com sua base epistêmica (SANTOS, 2018).

Como dito anteriormente, a teoria decolonial contraria o entendimento restrito do colonialismo enquanto um projeto histórico datado e superado, exatamente por que entende que as práticas de dominação empreendidas pelo colonialismo não se restringem à dimensão política e econômica (colonização do poder), mas incorporaram também uma espécie de colonização das formas e dos modos de pensar (colonização do saber) e das formas de viver e existir (colonização do ser). Esse entendimento extrapola o sentido estrito do colonialismo e o próprio entendimento dos colonizados - aqueles aos quais Fanon (2010) chamou de "condenados da terra" -, que não compreendem mais sua libertação como um ato de maturidade política e intelectual (como quiseram os iluministas europeus do passado), mas como um processo autônomo de expurgo, subversão e emancipação da própria lógica da colonialidade e da matriz cognitiva do Velho Mundo (WALSH, 2013; LANDER, 2000).

A superação das condições de vulnerabilidade, violência, desumanização por parte dos sujeitos colonizados não poderá ser satisfeita, segundo a teoria decolonial, pela mera superação das condições objetivas do colonialismo, exatamente por que o 
colonialismo não se restringe a um conjunto de condições objetivas. Ele é um projeto muito mais ambicioso de dominação que, sob o discurso da universalidade e da cientificidade, empreendeu um programa de hierarquização da humanidade que culminou com a produção de práticas sistemáticas de negação, destruição e aniquilamento do "outro" - aquele que não age, não pensa e, portanto, não se parece com nenhum de "nós" e, por isso mesmo, não deve ou não pode existir. É por esse ângulo que os pensadores da decolonialidade afirmarão que a máxima cartesiana do "penso, logo existo", representação máxima do advento da modernidade e de suas diferenciações (DESCARTES, 2001; CÈSAIRE, 2006), na verdade, mais esconde do que, de fato, revela a face mais perniciosa do colonialismo - o entronizamento do homem branco europeu e depois, do estadunidense, como referência e ápice do desenvolvimento humano. Eles são, dentro desse projeto de dominação, o tamanho e a régua para medir a tudo e a todos, da economia à subjetividade, da ciência ao direito, excluindo da condição de humanidade os indivíduos e as sociedades ditas "atrasadas", "pré-modernas", "pré-científicas" ou até mesmo "primitivas".

Para além da condição privilegiada de parâmetro, o colonialismo embute dentro do argumento da superioridade branca eurocêntrica e estadunidense, a justificativa necessária para o aniquilamento daquele que é "estranho" e, portanto, "diferente" - o entendimento de que a colonização é, de fato, um projeto necessário, um ato benevolente do colonizador que despertará os povos "adormecidos" do Novo Mundo, que atravessam a história sob a letargia da indisciplina e sobrevivem à mercê da ignorância. Este empreendimento, creem os desenvolvimentistas e racionalistas modernos, não será tarefa fácil, nem tão pouco, pacífica, visto que a colonização destes povos requer o braço enérgico da metrópole em nome da concessão de uma benesse maior - a modernização. É desse modo, à solavancos, que as sociedades do Novo Mundo são empurradas dentro dos desígnios do sistema-mundo mercantil-capitalista que começa a se constituir neste período. E foi assim que universalismo filosófico europeu da era moderna foi englobado pela lógica excludente do projeto colonial, uma vez que a prática sistemática do escravismo contra os povos africanos e o etnocídio das populações originárias no mesmo período, reiteraram o princípio da negação da humanidade àqueles que não se enquadravam dentro do projeto racionalista moderno (GILROY, 2001; GROSFOGUEL, 2016).

Conforme Quijano (1991), a colonialidade, enquanto permanência da estrutura de poder colonial, tem por base a racialização das relações de produção, o 
eurocentrismo como forma de produção das subjetividades e das existências e a hegemonia do Estado-nação que, após a superação do pacto colonial, se constitui como periferia do capitalismo global. Seria través desses pilares que o projeto colonial se manteria vivo, concretizando-se através da colonialidade do ser e do saber. É por isso que a analítica decolonial não se entende como um empreendimento exclusivamente teórico, mas também como um projeto de intervenção sobre a realidade. A teoria nos convida a refletir sobre essa realidade, constituindo-se enquanto plano político e acadêmico, a partir do qual, seria necessário, antes de mais nada, executar um expressivo esforço reflexivo que nos possibilitasse colocar em evidência as condições estruturais que suportam esse processo de reificação - a compreensão da lógica imanente da colonialidade (DUSSEL, MENDIETA \& BOHÓRQUEZ, 2011). Em que consistiria exatamente essa lógica da colonialidade? Que relação esse termo guardaria com o conceito de colonialismo? Qual o sentido atribuído à descolonização e por que estes teóricos não aceitam que a decolonialidade seja entendida como um mero sinônimo de descolonização? Esses conceitos, à despeito de elementares para a pesquisa decolonial, não compreendem um todo fechado e limitado, pelo contrário; é sabido que os mesmos se encontram em processo constante de discussão e revisão. Todavia, tomaremos aqui por base algumas referências consensuais por julgarmos que estas distinções são importantes e pertinentes para o entendimento desse debate.

O colonialismo pode ser compreendido como o processo histórico de formação dos territórios coloniais (MALDONADO-TORRES, 2018; 2006). Por conseguinte, o colonialismo moderno pode ser entendido como os meios específicos pelos quais os impérios ocidentais colonizaram a maior parte do mundo a partir da "descoberta" do Novo Mundo. A colonialidade, por conseguinte, deve à noção de colonialismo, mas também a estende, posto que pode ser compreendida como algo ainda maior, a saber: uma lógica de desumanização de caráter globalizante, capaz de sobreviver até mesmo à independência política e econômica destes territórios (MALDONADO-TORRES, 2018; McEWAN, 2019). Os desdobramentos e as consequências tardias da institucionalização do escravismo entre os povos "descobertos" seria, por exemplo, um elemento-chave, para entender a dimensão e a capilaridade da colonialidade como um instituto que se funda na modernidade, mas que a atravessa. Seguindo esse raciocínio, portanto, os/as pensadores/as da decolonialidade compreendem a descolonização como o momento histórico em que os povos colonizados se rebelaram e se insurgiram contra suas exmetrópoles e ex-impérios e reivindicaram sua independência (DUSSEL, 2016). A 
descolonização compreenderia, portanto, a consciência e o reconhecimento do sujeito colonizado da sua condição de subordinação política e econômica e sua superação. A decolonialidade, por outro lado, compreenderia outro estágio dessa sujeição e se refere, mais precisamente, à luta contra a lógica da colonialidade e seus efeitos materiais, epistemológicos e simbólicos ${ }^{1}$.

É fundamental para a teoria decolonial que a decolonialidade não seja resumida à descolonização e isso não se trata de mero preciosismo intelectual. Enquanto o colonialismo guarda uma dimensão histórica e empírica forte, a noção de colonialidade é trazida por estes teóricos como algo que vem embutido dentro da própria modernidade. Por essa razão, não é objetivo do pensamento decolonial alcançar, para os sujeitos colonizados, um projeto diferente de modernidade, mas a bem da verdade, suplantar a modernidade por algo que seja maior do que ela própria, pois reconhecem que a própria ideia de modernidade compõe parte intrínseca do projeto colonial de dominação. É essa luta por algo que possa transcender a noção de modernidade ocidental e garantir uma nova ordem mundial e a criação de um mundo onde mundos diferentes possam existir, coexistir e se relacionar, que se tem chamado de decolonialidade. A decolonialidade seria, portanto, essa atitude radical e de ruptura contra narrativas e concepções de tempo, espaço e de subjetividades que padronizaram a Europa, e depois os Estados Unidos, como o palco privilegiado da civilização humana em detrimento de todos os demais ${ }^{2}$ (MIGNOLO, 2010).

Um dos grandes méritos desse exercício elucidativo da decolonialidade é transformar o entendimento da questão racial, que sob essa perspectiva deixa a posição de tema subsidiário da grande empresa mercantil-capitalista e passa à condição de

\footnotetext{
${ }^{1}$ Descolonial, em seu sentido de desfazer o colonial encontra maior significado como contraposição ao colonialismo e não à noção de colonialidade. A ideia de colonialidade decorre do fato de que os processos de descolonização não resultaram em mundos descolonizados. Por esse motivo, a noção de decolonialidade é como uma espécie de segunda descolonização, sendo dirigida à análise e à crítica das múltiplas relações hierárquicas de raça, classe, gênero e sexualidade, bem como das epistemologias eurocêntrica hegemônicas que a primeira descolonização deixou intactas.

2 Para alguns intelectuais do grupo M/C, a expressão descolonial é algumas vezes tratada como sinônimo de decolonial. Contudo, pode-se observar nesta literatura, que há entre os autores $\mathrm{m}$ consenso hegemônico, visto que o próprio movimento não é unívoco. Dessa forma, cabe ainda perguntar: como diferenciar descolonial de decolonial? Argumentamos, a partir de alguns desses autores, que o decolonial encontra base no compromisso teórico e prático de aprofundar o entendimento de que o processo de colonização ultrapassou as esferas econômica e política, chegando à existência/essência dos povos colonizados, mesmo após o colonialismo ter se esgotado enquanto empreendimento histórico nestes territórios. Decolonialidade, nesse sentido, seria a contraposição à colonialidade. Já o descolonial poderia ser compreendido como uma contraposição ao colonialismo, já que o termo descolonização é a expressão mais recorrentemente utilizada para nos referirmos ao processo histórico de ascensão dos Estados-nação vítimas do colonialismo.
} 
dimensão estruturante do sistema-mundo. Dirão os teóricos da decolonialidade que foi o escravismo dos povos africanos e o etnocídio das populações originárias da América, o princípio e o epicentro em torno do qual a modernidade se constituiu e a partir do qual se constituiriam outras formas e modalidades de hierarquização das sociedades humanas, como a divisão internacional do trabalho, das hierarquias epistemológicas, sexuais, de gênero, religiosas, culturais, etc. (FANON, 2003; GILROY, 2001; GROSFOGUEL, 2016). Estes autores não desprezam a importância e o papel do modo de produção capitalista durante a modernidade, mas destacam que para além do advento do capitalismo, o mundo que se constitui com o advento da modernidade, só foi possível graças à centralidade que a noção de raça passou a ter a partir de então, sendo imposta do "centro" para a "periferia", como um parâmetro "científico" capaz de distinguir os humanos dos ditos não-humanos e oferecer a justificativa "racional" que legitimaria o direito a vida de uns e não dos outros.

Para além da possibilidade de outorgar a humanidade ou não aos sujeitos, a incorporação da noção de raça ao cerne da modernidade europeia gerou ainda outros desdobramentos cognitivos e geopolíticos, como uma espécie de demarcação política do conhecimento, determinando e autorizando quem são aqueles indivíduos que podem formular um conhecimento científico legítimo (GROSFOGUEL, 2016). Como corpos não ocupam o vácuo, a extensão dessa demarcação acabou por confeccionar ainda uma geopolítica do conhecimento, estabelecendo a Europa e, posteriormente, os Estados Unidos não somente como lócus tradicionais de emanação do poder, mas também como centros privilegiados de produção e promoção do conhecimento. Essa colonização etnocêntrica do saber garante que a experiência do conhecimento se restrinja às sociedades e culturas ditas do "centro", que pressupõe que outras sociedades e culturas que não as do "centro", restando às da periferia, a subordinação epistemológica e cognitiva - a parte menos visível, mas nem por isso menos importante da relação de dependência imposta pela lógica colonial.

$\mathrm{Na}$ seção seguinte, começaremos por nos voltar novamente a esse problema ontológico, especialmente, no que concerne ao sentido imanente do racionalismo cartesiano, pois entendemos que é a partir dele, em algum sentido, que a violência se constituiu e se institui como motor do projeto colonial. Reiteramos que essas práticas de violência, embora pareçam, ao leitor desavisado, referências a um passado longínquo e superado; na verdade, guardam extrema familiaridade com a perpetuação de práticas extensivas de violência sistêmica, sobretudo na América Latina - reconhecidamente, a 
região mais violenta do mundo. Segundo dados do Latinobarómetro para o ano de 2019, embora a América Latina abarque apenas $8 \%$ da população mundial, do total de homicídios registrados no mundo naquele ano, 37\% destas mortes vitimaram vidas latino-americanas (LATINOBARÓMETRO, 2020). E o caldo dessa violência estruturante não acaba por aí, o subcontinente guarda ainda uma posição de liderança não somente em relação às taxas de homicídio, mas também em relação aos casos de abuso das forças policiais, de tortura, de violências sexuais, de feminicídios, de crimes homofóbicos e lesbofóbicos, além das práticas veladas de segregação racial e de genocídio étnico a que estão submetidos, especialmente, os nossos/as jovens negros/as periféricos/as e os povos originários (NASCIMENTO, 1978; CARVALHO, 2006).

\section{Da guerra justa à violência sistêmica}

O prisma cartesiano do "penso, logo existo", parte da hipótese de que é possível construir um conhecimento universal, para além de determinações físicas ou espaciais (BERNARDINO-COSTA, MALDONADO-TORRES \& GROSFOGUEL, 2018). Um dos problemas mais elementares dessa tradição racionalista, segundo os pensadores da decolonialidade, é a ideia de que tudo que é produzido a partir dessa perspectiva tem uma validade que se impõe como universal. A grande questão por trás deste problema é o fato de que esse pretenso universalismo não se imprime sobre uma noção igualmente universal de humanidade, muito pelo contrário; ela se apoia sobre uma perspectiva etnocêntrica, racial e misógina de homem, mas por quê? Por que esse racionalismo moderno se ampara sobre um contexto histórico e político que tomou por referência a exploração, a desumanização e a escravização dos povos indígenas e africanos (FANON, 2003; CÉSAIRE, 2006; WALSH, 2013). Em outros termos, podemos afirmar que o projeto cartesiano de racionalização desencadeou um programa de extermínio do "diferente" que tomou por base o princípio de que aqueles que não pensam igual a mim, por dedução, não pensam e, por conseguinte, nem mesmo existem. A América Latina e a África, consequentemente, seriam as regiões do globo onde habitariam este não-ser, este não-humano. O lugar onde viviam e de onde provinham aqueles aos quais não lhes foi facultada qualquer capacidade cognitiva e que, por isso mesmo, seriam tão distantes do ideal de humanidade branco, androcêntrico e europeu. 
A esses não-sujeitos não restaria outra opção, dentro da lógica colonial, além da condição ou posição de meros consumidores dos modelos de desenvolvimento político, econômico, cultural e científico dos países norte-cêntricos (QUIJANO, 1991). É essa a grande falácia do universalismo abstrato da razão cartesiana, o fato de que ele esconde sob o discurso do ecumenismo, as bases de uma política restritiva que, de modo algum, pensa a inclusão das diferenças. Essa política, dirão os teóricos da decolonialidade - e talvez nesse ponto eles avancem para além da crítica da descolonização - é perniciosa não por que ela limita o acesso dos colonizados a esses bens, mas por que nega aos colonizados a condição de membros da própria humanidade. Não se trata somente de negar ou obliterar o acesso a algo, mas aniquilar e destruir as condições de reconhecimento desse "outro", tido como "estranho" e, portanto, "diferente", "nãohumano". Essa transmutação ontológica de sentido da humanidade de algo universal, para um entendimento restrito de humano, representou uma verdadeira ruptura moral que abriria passagem para as maiores atrocidades e as práticas mais inomináveis de violência até então conhecidas no curso da história humana.

A essa ruptura moral, Maldonado-Torres (2018; 2006) dará, por exemplo, o nome de "catástrofe metafísica". Para o autor, a catástrofe demográfica que se abateu sobre os povos do Novo Mundo a partir da chegada dos europeus só seria possível graças à catástrofe metafísica, fundada a partir da modernidade, seria a principal responsável por promover um deslocamento, ou melhor seria chamar de distorção, da noção medieval e cristã de humanidade. Não que não houvessem no mundo medieval distinções e classificações hierárquicas entre os grupos humanos, todavia, nos dirá o autor, em alguma medida, essas diferenciações eram contidas ou refreadas pela ideia monoteísta de um Deus que criou tudo e todos e pela noção de uma cadeia de seres que ligaria toda essa criação ao Divino. Esse sentido de "unidade", que teria raízes nas Escrituras Sagradas seria, portanto, até o advento da modernidade, o garantidor de uma unidade entre os humanos; unidade essa que admitia que os sujeitos, embora pudessem se diferenciar pela crença ou pela posição social, um princípio moral agregador os reconectava.

É importante dizer com isso que não se quer aqui, estabelecer uma distinção entre o medievo e a modernidade, como se o primeiro se constituísse enquanto uma sociedade mais harmônica porque apoiada sobre princípios universalistas da teologia cristã. Mas sim, destacar o quanto, apesar de imaterial, a dilatação desse princípio moral foi capaz, a partir do chamada "descoberta" do Novo Mundo, de implantar uma noção 
cada vez mais hierarquizante e utilitária de humanidade, não mais diferenciada ou classificada a partir de crenças divergentes, mas agora, apartada por essencialidades insolúveis e incontornáveis. É esse reordenamento das relações humanas que a teoria decolonial quer nos chamar atenção, apontando para o quanto a "descoberta" das Américas representou, para o racionalismo moderno europeu, a possibilidade experimental de empreender uma nova cosmologia do mundo, substituindo a antiga dualidade Eu-Outro pela lógica do Senhor-Escravo. A estes Senhores cabia a condição de seres e, portanto, de humanos enquanto, aos Escravos, sobrava a posição de nãohumanos e toda essa diferenciação irá se impor não pela força da crença, mas pela confiança "racional" dos modernos sobre princípios de "validação" e de "cientificidade".

A Europa medieval conheceu práticas extensivas de violência, especialmente, os conflitos oriundos do confronto entre o mundo cristão ocidental e o mundo mulçumano oriental. Todavia, estamos falando de guerras orientadas pela defesa dos territórios sagrados da cristandade - não que isso justifique a violência da cristandade contra os mouros e vice-versa, mas havia ali ainda, algum parâmetro de justificação legal. No caso da violência perpetrada contra os povos colonizados, estamos falando de uma violência diferenciada. Trata-se da violência contra aqueles que não são seres e, portanto, não são humanos (GROSFOGUEL, 2016). Se assim podemos falar, é uma violência ainda pior, porque é a violência infligida sem qualquer resquício de culpa, sem qualquer necessidade de justificativa legal. Isso se tornou parte de um modo operacional e comportamental das metrópoles e dos colonizadores que levou a excepcionalidade da guerra à condição de paradigma permanente do colonialismo, tornando-se mesmo, uma maneira natural dos colonizadores se comportarem em relação aos povos colonizados, “descobertos" e escravizados (MALDONADO-TORRES, 2018).

Essa institucionalização do paradigma da "guerra justa" contra os colonizados, essa normalização da situação de guerra, é que estamos chamando de naturalização da guerra. Não é uma guerra restrita a um território, muito menos uma guerra limitada pelo tempo - uma vez que os alvos privilegiados deste passado, são os mesmos do tempo presente. Na verdade, é uma guerra contra as populações colonizadas e contra aqueles que se identificam como seus descendentes. Essa ideia de uma guerra "justa" e "permanente", além de desresponsabilizar a empresa colonial das violências perpetradas contras estas populações, instituiu uma noção limitada e maniqueísta do mundo onde os colonizadores figuram como benevolentes e os colonizados, como indóceis, sendo a 
violência, a única via "pedagógica" possível de realização da aventura civilizatória. Dentro dessa lógica, não é a exploração do trabalho forçado ou a acumulação primitiva do capital que justifica a prática endêmica da violência contra o povo colonizado; os próprios sujeitos colonizados é que são a razão final dessa violência. É uma violência contra a essência desses sujeitos e por isso mesmo, estamos falando de práticas de violência tão difíceis de serem superadas na região, e que sobrevivem à despeito do advento da democracia eleitoral ou mesmo da institucionalização de garantias constitucionais.

Nas palavras de Dussel (2000), o que a dominação colonial traz de novo (e a colonialidade a mantém), é a transformação do racismo em princípio organizador das múltiplas hierarquias do sistema-mundo. A modernidade estaria assentada sobre uma leitura de raça para o qual não há precedentes na história, sendo essa a principal justificativa da "práxis irracional da violencia", ocultada e camuflada pelo mito do desenvolvimento (DUSSEL, 2000; BALLESTRIN, 2013). Para o homem europeu moderno, a "culpa" desta violência é do próprio "bárbaro", que se opõe ao "processo civilizador", que não reconhece os "ganhos" da modernidade e que, pela sua ignorância, deverá arcar com os "custos" do seu "atraso". O sofrimento, a dor e a morte, desta forma, são tratados como inevitáveis, uma espécie de sacrifício emancipador das vítimas. Aos algozes destas, no entanto, cabe a posição de sujeitos moralmente superiores, capazes de tudo (e de todas as violências) em prol da superação do atraso dos povos "imaturos" (os africanos, os povos originários, as mulheres, as crianças, os homossexuais etc.). $\mathrm{O}$ homem branco/heterossexual/patriarcal/cristão/militar/capitalista europeu é, para essa narrativa, o grande herói civilizador.

O outro lado constitutivo do paradigma da "guerra justa", instituído pela colonialidade, e que se amplifica nas situações de violência endêmica nos povos de herança colonial, compreende ainda as lógicas inerentes às dinâmicas de gênero. Num primeiro momento, o colonizado é entendido, muitas vezes, como uma espécie animal, portanto, destituído de gênero e de qualquer diferença sexual por parte do colonizador. Em outros momentos, essa naturalização da guerra é a principal responsável pela formalização de padrões de sexo e gênero, visto que é a partir da modernidade, que determinados padrões, antes restritos aos cenários de guerra, passaram a ser estandardizados como modelos de masculinidade de feminilidade (GROSFOGUEL, 2016; LUGONES, 2007; 2008). Foi assim que as guerras do mundo ocidental moderno instituíram a ideia do corpo masculino como o corpo guerreiro, aquele que vai à guerra, 
o corpo que ameaça; enquanto o corpo feminino, aquele que permite a reprodução, que empreende os cuidados, que carrega a memória do grupo. Não por acaso, na "guerra justa", sobre os corpos colonizados de homens e mulheres, pairavam flagelos distintos que, em essência, respondiam à atribuição que a economia da guerra instituía aos gêneros - aos corpos dos homens, a tortura, a castração e outras formas de mutilação de membros, bem como a morte; aos corpos das mulheres, além da tortura e da morte, a ameaça premente do estupro.

Dentro dessa lógica da colonialidade, a agressividade masculina torna-se uma constante, reproduzindo-se ainda contra todos os corpos daqueles que não correspondem ao ideal masculino do mundo "civilizado". O modelo de feminidade aqui é o da esposa, que cuida do marido, que gera a prole de novos homens, que se quer submissa e sujeita aos desígnios do homem e do Estado. Os corpos de homens e mulheres que se desviam desse modelo, tornam-se ainda mais vulneráveis, absolutamente descartáveis, indignos de qualquer respeitabilidade - A quem serve uma mulher que não é reprodutora? A quem serve um homem que não é guerreiro? É importante destacar que estes modelos de masculinidade e de feminilidade impostos pelo colonizador não correspondem aos modelos e representações de gênero originários das sociedades "descobertas" (OYHANTCABAL, 2021). Contudo, sua imposição sistemática acaba por promover uma normalização também dos modelos de sexo e gênero entre os colonizados que, não por acaso, tomam estas referências como parâmetros para suas performances. Isso acaba por intensificar a perpetuação da agressividade e da belicosidade, tornando isso um dínamo das relações sociais entre colonizadores e colonizados e entre os próprios colonizados, reforçando um ciclo ininterrupto de violências.

Essa violência é justificada pela ausência de humanidade dos seus corpos. Na verdade, essa lógica categorial dicotômica entre Humano/Não-humano é o ponto central do pensamento capitalista e colonial moderno e é a partir dela que se estabelece não somente uma hierarquia entre raças, gêneros e sexualidades, mas também se determina ou se autoriza a morte, o extermínio e a escravidão dos povos colonizados. Trata-se de um sistema binário, racializado, heteronormativo e capitalista que está longe de ser um mero tipo ideal de sujeito e humanidade, mas sim um modelo impositivo e normatizador das existências, que visa disciplinar, controlar, padronizar as formas de vida diferentes por meio da violência e do aniquilamento. É nesse sentido que as tradições subalternas do movimento feminista latino-americano (BALLESTRIN, 2020; SANTOS, 2018), 
destacarão o gênero como uma categoria também "inventada" pelo projeto colonial e vinculada, umbilicalmente, ao fenômeno da racialização.

Dentro dessa perspectiva, não se pode compreender a discriminação de gênero sem perceber a indissociabilidade entre este e a noção de raça no contexto do capitalismo. Aliás, a partir destes/as autores/as, pode-se até mesmo afirmar que sem o racialismo, o projeto de acumulação primitiva do colonialismo não teria sido possível. As categorias raciais e de gênero surgiram durante o colonialismo como eixos fundamentais a partir dos quais foi estruturado um modelo de exploração e estratificação da sociedade (OYĚWÙMÍ, 2004). A violência das relações patriarcais vivenciadas hoje pelos povos afro-americanos, especialmente pelas mulheres negras, dentro e fora da África, confirmariam não somente o quanto essa violência deita raízes no passado colonial, mas também, o quanto o gênero é um aspecto intrínseco da colonialidade. É nesse sentido que autoras como Patrícia Collins (1997) argumentam que, para uma transgressão contra-colonial, é necessário compreender raça, classe, gênero e sexualidade como formas interseccionais de dominação, legadas pelo passado colonial, mas até hoje, constitutivas e atuantes dentro da estrutura social dos povos colonizados.

É esperado, da perspectiva da "guerra justa", que os colonizados sejam dóceis, que não resistam, mas se o fazem, a violência da represália da metrópole pode ser ainda maior, como é fartamente descrita pela historiografia dos países de herança colonial, a saber: os meios sanguinários com que focos de resistência negra ou indígena foram sufocados pelas coroas europeias durante o colonialismo. Essas observações da teoria são especialmente importantes para pensar a perpetuação hoje de práticas veladas e institucionalizadas de violência contra grupos vulneráveis, especialmente nos países latino-americanos. Os teóricos da decolonialidade vão propor a reflexão de que essa violência não é uma resposta a conflitos específicos, mas algo que se institui a partir da modernidade e da colonialidade como a ordem irresistível e irreversível da natureza e do mundo, contra a qual não se pode lutar por que é inexorável e ininterrupta. Aqui, os grupos menos favorecidos e que contraiam a ordem e essa visão de mundo continuamente estável são vistos como uma ameaça à ordem colonial, à modernização da sociedade ou mesmo à democracia eleitoral, à segurança coletiva ou à paz social, cabendo ao Estado, a função "preventiva" de proteger-nos destes sujeitos, potencialmente violentos e descontrolados, um condenado na fenomenologia-existencial fanoniana, para o qual não há outra solução que não o controle ou o aniquilamento. 
O projeto colonial moderno estabelece uma linha ontológica que não distingue entre os Seres e os não-seres, a exemplo da diferença ontológica criada por Heidegger, mas sim uma divisão e diferenciação entre os Seres e os não-seres, ou seja, entre aqueles que são considerados humanos e aqueles que estão fora dessa esfera (MALDONADO-TORRES, 2007). Os europeus fazem da desigualdade humana um princípio de justificação e convencimento da sua superioridade humana, transformando a colonização do não-europeu não somente num processo de exploração, mas também de desumanização do colonizado. A instrumentalização das noções de raça e gênero aqui cumprem a função de fundamentar e autorizar a distinção entre aqueles que se pode/deve sujeitar, dominar e escravizar. Essa linha ontológica colonial-moderna, que fundamenta a desigualdade, a desumanização e a colonização na modernidade estabelece que a zona do Ser colonial é o espaço da vida, conquanto a zona do não-ser, é o território da morte ou da indiferença diante da morte (MALDONADO-TORRES, 2016).

A metáfora dos "condenados da terra" de Franz Fanon é de 1963, mas serve ainda hoje. São esses sujeitos, aqueles que ainda estão localizados fora do tempo e do espaço humanos, que não lhes foi garantida assumir a posição de produtores de conhecimento, cujas subjetividades são desprezadas e cujas vidas podem ser descartáveis. O condenado é um produto do intercruzamento das práticas de colonialidade do ser, do poder e do saber. Eles são permanentemente mantidos abaixo das dinâmicas usuais de acumulação e exploração do capital, cuja única possibilidade de ascensão só pode se dar pelos meios assimilacionistas que a lógica opressiva e escravista da colonialidade lhe oferece - o que reforça os mecanismos que garantem que o condenado se mantenha ainda mais separado e distante de si, e dos demais (FANON, 2008; FAUSTINO, 2015). É por isso que os teóricos da decolonialidade são categóricos em afirmar que esse reconhecimento de si e dos demais "condenados", passa, necessariamente, por uma atitude política, que deve compreender também uma fenomenologia, ou seja, uma atitude mental de auto-reconhecimento e também de reconhecer-se no outro, de revelar-se no outro - essa seria a via possível, segundo estes autores, de superação dos obstáculos interpostos pela lógica da modernidade e da colonialidade. 


\section{Considerações finais}

Aquilo que hoje se convencionou chamar de decolonialidade, "giro colonial" ou mesmo de projeto decolonial, abriga na verdade um núcleo comum, a saber: estamos falando de esforços teóricos e analíticos, mas também políticos, estético, artísticos e literários que têm por base, o entendimento comum de que a colonialidade compreende o lado obscuro e perverso da modernidade ocidental. Nesse sentido, a colonialidade não é um desvio ou uma corrupção do pretenso humanismo e do racionalismo universalista europeu. $\mathrm{Na}$ verdade, ela seria parte constitutiva da própria modernidade.

Entendida muitas vezes, especialmente pelos seus detratores, como uma espécie de retorno à luta de libertação nacional das antigas colônias europeias, a teoria decolonial está longe de ser resumida às lutas de descolonização e liberação nacionais. $\mathrm{Na}$ verdade, o movimento decolonial toma o colonialismo por referência, mas extrapola seu entendimento restrito a uma dimensão temporal ou espacial e compreende o mesmo como um fenômeno maior e mais sofisticado de subordinação e sujeição daqueles que não são brancos, europeus, heterossexuais ou do sexo masculino, à condição de desumanidade.

É imprescindível destacar que a crítica que se elabora sobre os limites da universalidade do pensamento europeu moderno põe em relevo as contradições imanentes de um projeto de humanidade restritivo e apoiado sobre o racismo, sobre a escravização praticadas contra os povos africanos, sobre a discriminação de gênero e sobre o etnocídio das comunidades originárias. Esta crítica não se limita tão somente a denunciar estas ambiguidades, mas também a problematizar sua longa duração, especialmente nas sociedades de herança colonial, apontando para os fatores que, sistematicamente, têm contribuído para a perpetuação dessas violências - a própria dificuldade dos colonizados de superar a modernidade a partir de limites epistemológicos que lhe são impostos de cima para baixo. É contra esses limites epistemológicos que o movimento decolonial rebela-se e é contra ele que seus autores objetivam não a constituição de uma nova modernidade, mas sim a superação radical e irrestrita de toda e qualquer forma de desumanização ou de supressão da humanidade aos sujeitos.

Esta proposição da teoria decolonial é, por si, analítica, mas é também política. No campo da investigação histórica e social, é um convite à realização de pesquisas que 
confrontem e afrontem a padronização de objetos, recortes e métodos de pesquisa convencionais. É uma proposta de ressignificação do olhar sobre a agência social dos grupos historicamente vulneráveis e menos favorecidos, mas é também uma proposta de enegrecimento e de transformação dos nossos currículos escolares e universitários. No plano mais específico da pesquisa sobre violência, é uma proposta de desnaturalização das práticas ininterruptas de violência que caracterizam as antigas colônias europeias, especialmente, os países latino-americanos, que foram, por séculos, o laboratório por excelência da colonialidade europeia. Trata-se de um projeto teórico e político ambicioso que visa implodir o modelo cartesiano moderno de ser e pensar, para reconhecer e incorporar a contribuição do olhar e do pensamento de homens e mulheres negros/as, indígenas, não-heteronormativas e de outros grupos historicamente silenciados, tomando por base suas experiências vividas, sua própria historicidade e suas experiências políticas dentro desse sistema-mundo.

\section{Referências bibliográficas}

ARROYO, M. G. (2011). Outros Sujeitos, Outras Pedagogias. Petrópolis: Vozes.

BALlESTRIN, L. (2013). América Latina e o Giro Decolonial. Revista Brasileira de Ciência Política, vol. 1: 89-117.

(2020). Feminismo De(s)colonial como Feminismo Subalterno LatinoAmericano. Revista Estudos Feministas, vol. 3: 1-14.

BERNARDINO-COSTA, J.; MALDONADO-TORRES, N.; GROSFOGUEL, R. (Orgs.) (2018). Decolonialidade e Pensamento Afrodiaspórico. Belo Horizonte: Autêntica.

CARVALHO, J. J. (2006). Inclusão Étnica e Racial no Brasil: A Questão das Cotas no Ensino Superior. São Paulo: Attar Editorial.

CASTRO-GOMEZ, S.; GROSFOGUEL, R. (Eds.) (2007). El Giro Decolonial: Reflexiones para una Diversidad Epistémica más Allá del Capitalismo Global. Bogotá: Universidad Javeriana y Siglo del Hombre Editores.

CÈSAIRE, A. (2006). Discurso Sobre el Colonialismo. Madrid: Ediciones Akal.

COLLINS, P. H. (1997). Comentário Sobre o Artigo de Hekman "Thuth and Method: Feminist Standpoint Theory Revisited": Onde está o poder? Signs, n. ${ }^{\circ}$ 22, vol. 2: 375-380.

DESCARTES, R. (2001). Discurso do Método. São Paulo: Martins Fontes.

DUSSEL, E.; MENDIETA, E.; BOHÒRQUEZ, C. (Eds.) (2011). El Pensamiento Filosófico Latinoamericano, del Caribe, y "Latino" (1300-2000). Mexico D.F.: Siglo Veintiuno Editores.

DUSSEL, E. (2016). Transmodernidade e Interculturalidade: Interpretação a Partir da Filosofia da Libertação. Sociedade \& Estado, Brasília, v. 31, n. 1: 49-71.

(2000). "Europa, Modernidad y Eurocentrismo". In: LANDER, E. (Org.). La Colonialidad del Saber: Eurocentrismo y Ciencias Sociales: Perspectivas Latinoamericanas. Buenos Aires: Clacso. 
ESCOBAR, A. (2003). Mundos y Conocimientos de Otro Modo: El Programa de Investigación de Modernidad/Colonialidad Latinoamericano. Tabula Rasa, Bogotá, n. 1: 51-86.

FANON, F. (2003). Os Condenados da Terra. Juiz de Fora: Editora UFJF. (2008). Pele Negra, Máscaras Brancas. Salvador: Ed. da UFBA.

FAUSTINO, D. M. (2015). "Por que Fanon? Por que agora?": Frantz Fanon e os Fanonismos no Brasil. São Carlos: UFSCar. Tese (Doutorado em Sociologia) Programa de Pós-Graduação em Sociologia, Universidade Federal de São Carlos.

GILROY, P. (2001). O Atlântico Negro: Modernidade e Dupla Consciência. São Paulo: Editora 34; Rio de Janeiro: Universidade Cândido Mendes, Centro de Estudos Afro-Asiáticos.

GROSFOGUEL, R. (2016). A estrutura do Conhecimento nas Universidades Ocidentalizadas: Racismo/Sexismo Epistêmico e os Quatro Genocídios/Epistemicídios do Longo Século XVI. Sociedade \& Estado, Brasília, v. 31, n. 1: 23-47.

KILOMBA, G. (2016). Descolonizando o Conhecimento - Uma Palestra-Performance. (J. Oliveira, Trad.). Recuperado de https://www.geledes.org.br/descolonizandooconhecimento-uma-palestra/

LANDER, E. (Ed.) (2000). La Colonalidad del Saber: Eurocentrism y Ciencias Sociales: Perspectivas Latinoamericanas. Caracas: Facultad de Ciencias Económicas: IESALC.

LATINOBARÓMETRO (2020). Informe Latinobarómetro 2020. Buenos Aires: Corporación Latinobarómetro.

LUGONES, M. (2007). Heterosexualism and the Colonial/Modern Gender System. Hypatia, v. 22, n. 1: 186-209. . (2008). Colonialidad y Género. Tabula Rasa, Bogotá, n. 9: 73-101, jul./dez.

MALDONADO-TORRES, N. (2018). "Analítica da Colonialidade e da Decolonialidade: Algumas Dimensões Básicas". In: BERNARDINO-COSTA, Joaze; MALDONADO-TORRES, N.; GROSFOGUEL, R. (Orgs.) Decolonialidade e Pensamento Afrodiaspórico. Belo Horizonte: Autêntica: 31-61. (2016). Transdiciplinariedade e Decolonialidade. Sociedade \& Estado, Brasília, v. 31, n. 1: 75-97. (2006). "Césaire y la Crisis del Hombre Europeo". In: CÉSAIRE, Aimé. Discurso Sobre el Colonialismo. Madrid: Ediciones Akal, p. 173-196.

(2007). On the Coloniality of Being: Contributions to the Development of a Concept. Cultural Studies, v. 21, n. 2-3: 240-270.

McEWAN, C. (2019). Postcolonalism, Decoloniality and Development. London and New York: Routledge Perspectives on Development.

MIGNOLO, W. (2010). Desobediência Epistêmica: Retórica de la Modernidad, Lógica de la Colonialidad, y Gramática de la Descolonialidad. Buenos Aires: Ediciones del Signo.

(2008). Desobediência Epistêmica: A Opção Descolonial e o Significado de Identidade em Política. Cadernos de Letras da UFF - Dossiê: Literatura, Língua e Identidade, vol. 34: 287-324.

(2007). El Pensamiento Decolonial: Desprendimiento y Apertura. Un Manifiesto. In: GÓMEZ, S. C. \& GROSFOGUEL, R. (Orgs.). El Giro Decolonial: Reflexiones para una Diversidad Epistémica más Allá del Capitalismo Global. Bogotá: Siglo del Hombre Editores; Universidad Central, Instituto de Estudios Sociales Contemporáneos y Pontificia Universidad Javeriana, Instituto Pensar, p. 25-46. 
NASCIMENTO, A. (1978). O Genocídio do Negro Brasileiro: Processo de um Racismo Mascarado. Rio de Janeiro: Paz e Terra.

OYĚWÙMÍ, O. (2004). Conceituando o Gênero: Os Fundamentos Eurocêntricos dos Conceitos Feministas e o Desafio das Epistemologias Africanas. Codesria Gender Series, v. 1: 1-8.

OYHANTCABAL, L. M. (2021). Los Aportes de los Feminismos Decolonial y Latinoamericano. ANDULI, vol. 20: 97-115.

QUIJANO, A. (1991). Colonialidad y Modernidad/Racionalidad. Perú Indígena, n. 29: 11-20.

SANTOS, V. M. (2018). Notas Desobedientes: Decolonialidade e a Contribuição para a Crítica Feminista à Ciência. Psicologia \& Sociedade, vol. 30: 1-11.

WALSH, C. (Org.). (2013). Pedagogías Decoloniales: Prácticas Insurgentes de Resistir, (Re)Existir, y (Re)Vivir. Quito: Ediciones Abya Yala, v. 1.

Artigo recebido em 2 de janeiro de 2021.

Aprovado em 18 de junho de 2021.

DOI: $10.12957 /$ intellectus.2021.58456 